\title{
A study of lipid profile in chronic kidney disease in pre- dialysis patients
} Choudhary N. ${ }^{{ }^{*}}$

DOI: https://doi.org/10.17511/ijmrr.2019.i03.01

1* Nitin Choudhary, Resident, Department of General Medicine, R D Gardi Medical College, Ujjain, Madhya Pradesh, India.

Introduction: Longitudinal studies have established that Cardiovascular Disease (CVD) occur more frequently and are the leading cause of death in Chronic Kidney Disease (CKD). Dyslipidemia has been established as an important risk factor in the pathogenesis of CVD in CKD patients. Objectives: Present study was aimed to evaluate (in CKD patients), Demography along with Prevalence and Pattern of Dyslipidemiaand co-relation of Dyslipidemia with various CK Dstages. Methods: Present Cross-sectional study, conducted in Department of Medicine, R.D. Gardi Medical College and CRG hospital, Ujjain, M.P. from $1^{\text {st }}$ January 2015 to $31^{\text {st }}$ July 2016 . We studied 115 pre-dialysis CKDcases and 100 age \& sex matched controls. CKD was diagnosed as per 2012 KDOQI Criteria. Result: In CKD cases, maximum $23.47 \%$ cases belonged to fifth decade. Mean age was $48.99 \pm 16.74$. Male to Female ratio was1.21: 1 . Prevalence of individual dyslipidemias was High TC $=50.44 \%$, High TG $=67 \%$, High LDL-C $=42 \%$, High VLDL-C $=67 \%$ and Low HDL-C $=73.9 \%$. Overall, prevalence of dyslipidemia was $82.6 \%$. Significant increase in TG and VLDL-C and significant decrease in HDL-C was observed. TC and LDL-C were non- significantly increased.TC, TG, LDL-C and VLDL-C were in increasing trend with progression of CKD stages (3-5) and increased in Subgroup II (ESRD) as compared to Subgroup I (Non-ESRD), the increase being significant in case of TG and VLDL-C. HDL-C value was in decreasing trend with progression of CKD stages and significantly decreased in Subgroup II as compared to Subgroup I.TC, TG, LDL-C and VLDL-C showed negative correlation with GFR while HDL-C showed positive correlation. TG, HDL-C and VLDL-C showed highly significant correlation. HDL-C showed strongest correlation, followed by TG. Conclusion: Patients with CKD are predisposed to accelerated atherosclerosis leading to increased CVD. This study confirms the presence of atherogenic lipid profile in CKD.

Keywords: Chronic Kidney Disease, Cardio Vascular disease, Dyslipidemia

Corresponding Author

Nitin Choudhary, Resident, Department of General Medicine, R D Gardi Medical College, Ujjain, Madhya Pradesh, India.

Email: nitin6345@gmail.com

\section{How to Cite this Article}

Choudhary N. A study of lipid profile in chronic kidney disease in pre- dialysis patients. Int J Med Res Rev. 2019;7(3):150-156.

Available From

https://ijmrr.medresearch.in/index.php/ijmrr/article/ view/1051
To Browse

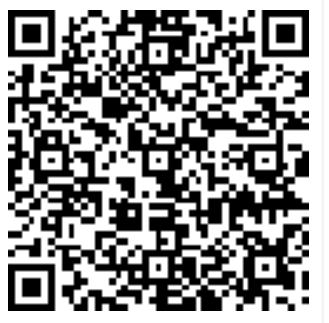

Manuscript Received 2019-04-27

Conflict of Interest No

Review Round 1
2019-05-06
Funding
Nil

Review Round 1 Nil

Review Round 2
2019-05-11
$\begin{gathered}\text { Ethical Approval } \\ \text { Yes }\end{gathered}$

Review Round 3

Accepted 2019-05-16

Plagiarism X-checker $7 \%$

Note

(c) 2019 by Nitin Choudhary and Published by Siddharth Health Research and Social Welfare Society. This is an Open Access article licensed under a Creative Commons Attribution 4.0 International License https://creativecommons.org/licenses/by/4.0/ unported [CC BY 4.0]. 


\section{Introduction}

Chronic kidney disease (CKD) encompasses a spectrum of different pathophysiologic processes associated with abnormal kidney function, and a progressive decline in glomerular filtration rate (GFR)[1]. Cardio-Vascular Disease (CVD) is the leading cause of death, irrespective of race and ethnicity, and is mostly caused by cardio-metabolic risk factors and chronic kidney disease (CKD)[2].

In the United States, the prevalence of CVD in CKD patients reaches $63 \%$, in contrast with only $5.8 \%$ in people without CKD, and this prevalence is directly correlated with the severity of CKD[3]. CVD accounts for $40 \%$ to $50 \%$ of deaths in dialysis patients.

In dialysis-dependent end-stage renal disease (ESRD) patients, the risk of cardiovascular (CV) mortality is 10 -fold to 20 -fold higher than in age and gender-matched control subjects without CKD[4]. The median survival of dialysis patients with baseline Heart Failure (HF) has been estimated to be 36 months, in contrast with 62 months for those without baseline HF[5]. Dyslipidemia has been established as a well-known traditional risk factor for CVD and large-scale observational studies have shown that total cholesterol (TC), high-density lipoprotein cholesterol (HDL-C) and low-density lipoprotein cholesterol (LDL-C) are most important independent predictors of cardiovascular morbidity and mortality [6]. Although there are many important risk factors playing a role in the pathogenesis of CVD in chronic kidney disease (CKD) patients, dyslipidemia represents one of the important and modifiable risk factor [7].

The prevalence of hyper-cholesterolemia ranges from $48 \%$ in CKD stage $1-2$ to $80 \%$ in CKD stage 34 [3]. Several prospective studies suggest that lipid abnormalities principally present in CKD is Hypertriglyceridemia along with increased Very-Low Density Lipoprotein Cholesterol (VLDL-C) and decreased HDL-C[8]. Abnormal lipid and lipoprotein concentrations in patients with CKD may be responsible for increased atherosclerosis and risk of CVD[9]. Elevated Triglyceride (TG) levels are due to impaired activity of Lipo-Protein Lipase (LPL) and direct inhibitory effect of various uremic 'toxins' on the enzymes involved in lipid metabolism [10]. Dyslipidemia has been observed to worsen with progression of CKD stagesleading to increased Cardio-Vascular morbidity and mortality [11].

\section{Objectives}

01. To study the Demography in Pre-dialysis CKD patients (Study cases).

02. To study the prevalence of Dyslipidemia in Study cases.

03. To study the pattern of Dyslipidemia in Study cases.

04. To study the correlation of Dyslipidemia in Study cases with various stages of CKD.

\section{Materials and Methods}

Study Setting: The present study was conducted in the Department of Medicine, R.D. Gardi Medical College and CRG hospital, Ujjain, M.P. from 1st January 2015 to 31 st July 2016. We studied 115 cases of CKD and 100 age \& sex matched controls. CKD was diagnosed by clinical examination, biochemical analysis and sonological findings as per the 2012 Kidney Disease Outcomes Quality Initiative (KDOQI) Criteria.

Study Design: The present study was a Crosssectional observational study.

Inclusion Criteria: All patients of Chronic Kidney Disease with age 18 years or above, who give consent for study.

\section{Exclusion Criteria}

01. Patients who do not fill the above criteria.

02. Patients with End Stage Renal Disease (CKDStage 5) on Hemodialysis.

03. Patients with Diabetes Mellitus.

04. Patients already on lipid lowering drug therapy.

Sampling methods: Blood samples were drawn from all the patients by venipuncture in cubital fossaafter a minimum of 12 hours of fasting. About $10 \mathrm{ml}$ of blood was drawn \& transfused to dried glass vials. Serum was separated within 2 hours after collectionand centrifuged at $5000 \mathrm{rpm}$ for 10 minutes. The supernatant clear serum was then pipetted out and stored in dry thin walled vials at $400 \mathrm{C}$. The samples were analysed on the same day.

Laboratory procedures: Study of lipid profile was done by VITROS slide method.

Ethical Clearance: Ethical clearance for the study was obtained from Ethical Committee, RD Gardi Medical College, Ujjain 
Surgical procedure, if any: None

Statistical analysis: Statistical software SPSS 23.0 was used for the analysis of data.

\section{Results}

Table-1: Age\&Gender-Wisedistribution\& mean age of Study group and Control group.

\begin{tabular}{|c|c|c|c|c|c|}
\hline \multirow[t]{2}{*}{$\begin{array}{l}\text { S. } \\
\text { No. }\end{array}$} & \multirow[t]{2}{*}{$\begin{array}{c}\text { Age group (in } \\
\text { years) }\end{array}$} & \multicolumn{2}{|c|}{$\begin{array}{l}\text { Study group } \\
\qquad(\mathbf{n = 1 1 5})\end{array}$} & \multicolumn{2}{|c|}{$\begin{array}{l}\text { Control group } \\
\qquad(n=100)\end{array}$} \\
\hline & & $\begin{array}{l}\text { No. of } \\
\text { cases }\end{array}$ & Percentag & No. of cases & Percentage \\
\hline 1 & $18-20$ & 1 & 0.86 & 5 & 5 \\
\hline 2 & $21-30$ & 18 & 15.65 & 28 & 28 \\
\hline 3 & $31-40$ & 21 & 18.26 & 11 & 11 \\
\hline 4 & $41-50$ & 27 & 23.47 & 14 & 14 \\
\hline 5 & $51-60$ & 23 & 20 & 19 & 19 \\
\hline 6 & $61-70$ & 14 & 12.17 & 19 & 19 \\
\hline 7 & $>70$ & 11 & 9.56 & 4 & 4 \\
\hline 8 & Male & 63 & 54.8 & 54 & 54 \\
\hline 9 & Female & 52 & 45.2 & 46 & 46 \\
\hline 10 & $M: F$ & \multicolumn{2}{|l|}{$1.21: 1$} & \multicolumn{2}{|l|}{$1.17: 1$} \\
\hline 11 & Mean age (Overall) & \multicolumn{2}{|c|}{$48.99 \pm 16.74(20-92)$} & \multicolumn{2}{|c|}{$44.12 \pm 17.61(18-76)$} \\
\hline 12 & Mean age (Male) & \multicolumn{2}{|c|}{$53.55 \pm 16.37(21-92)$} & \multicolumn{2}{|c|}{$44.89 \pm 18.99(18-76)$} \\
\hline 13 & Mean ac & \multicolumn{2}{|c|}{$43.46 \pm 15.59(20-76)$} & \multicolumn{2}{|c|}{$43.21 \pm 16.01(21-72)$} \\
\hline
\end{tabular}

Table-2: Biochemical Parameters in Study group and Control group.

\begin{tabular}{|c|c|c|c|c|c|c|}
\hline \multirow[t]{2}{*}{$\begin{array}{l}\text { S. } \\
\text { No }\end{array}$} & \multirow[t]{2}{*}{$\begin{array}{l}\text { Biochemical } \\
\text { Parameter }\end{array}$} & \multicolumn{2}{|c|}{\begin{tabular}{|c} 
Study group \\
$(\mathrm{n}=115)$
\end{tabular}} & \multicolumn{2}{|c|}{$\begin{array}{c}\text { Control group } \\
(\mathrm{n}=100)\end{array}$} & \multirow[t]{2}{*}{$\begin{array}{l}\text { P-value for } \\
\text { Independent } t \text { - test }\end{array}$} \\
\hline & & Mean & S.D. & Mean & S.D. & \\
\hline 1 & Blood Urea & 204.75 & 84.12 & 14.11 & 4.34 & 0.000 \\
\hline 2 & $\begin{array}{l}\text { Serum } \\
\text { Creatinine }\end{array}$ & 8.34 & 4.55 & 0.75 & 0.29 & 0.000 \\
\hline 3 & \begin{tabular}{|l|} 
Serum Total \\
Proteins
\end{tabular} & 6.08 & 0.62 & 6.80 & 0.46 & 0.000 \\
\hline 4 & Serum Albumin & 3.33 & 0.53 & 4.23 & 0.33 & 0.000 \\
\hline 5 & Serum Sodium & 138.35 & 7.12 & 139.85 & 5.29 & 0.081 \\
\hline 6 & $\begin{array}{l}\text { Serum } \\
\text { Potassium }\end{array}$ & 5.51 & 1.27 & 4.28 & 0.71 & 0.000 \\
\hline 7 & Serum Calcium & 8.30 & 1.29 & 8.93 & 0.77 & 0.000 \\
\hline 8 & $\begin{array}{l}\text { Serum } \\
\text { Phosphorus }\end{array}$ & 7.29 & 2.13 & 3.66 & 0.83 & 0.001 \\
\hline 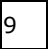 & Hemoglobin & 7.60 & 2.54 & 12.02 & 1.56 & 0.000 \\
\hline
\end{tabular}

A statistically highly significant increase in levels of Blood Urea, Serum Creatinine, Serum Potassium and Serum Phosphorus, while a statistically highly significant decrease in levels of Serum Total Proteins, Serum Albumin and Serum Calcium was observed in Study group. Serum Sodium level was decreased in Study group, but not significantly.
Table-3: Prevalence of Individual \& Overall Dyslipidemia in Study and Control group. Chisquare test was applied.

\begin{tabular}{|c|c|c|c|c|c|c|}
\hline \multicolumn{2}{|c|}{ Lipid profile parameter } & \multicolumn{2}{|c|}{ Study Group } & \multicolumn{2}{|c|}{ | Control Group } & \multirow[t]{2}{*}{ p-value } \\
\hline & & No. of cases & (\%) & No. of cases & $(\%)$ & \\
\hline \multirow[t]{2}{*}{ TC } & $\mid<200$ & 57 & 49.56 & 73 & 73 & \multirow[t]{2}{*}{0.000} \\
\hline & $\geq 200$ & 58 & 50.44 & 27 & 27 & \\
\hline \multirow[t]{2}{*}{ TG } & $<150$ & 38 & 33 & 70 & 70 & \multirow[t]{2}{*}{0.000} \\
\hline & $\geq 150$ & 77 & 67 & 30 & 30 & \\
\hline \multirow[t]{2}{*}{ HDL-C } & $<40$ & 85 & 73.9 & 20 & 20 & \multirow[t]{2}{*}{0.000} \\
\hline & $40-60$ & 30 & 26.1 & 80 & 80 & \\
\hline \multirow[t]{2}{*}{ LDL-C } & $<130$ & 67 & 58 & 69 & 69 & \multirow[t]{2}{*}{0.103} \\
\hline & $\geq 130$ & 48 & 42 & 31 & 31 & \\
\hline \multirow[t]{2}{*}{ VLDL-C } & $<30$ & 38 & 33 & 90 & 90 & \multirow[t]{2}{*}{0.000} \\
\hline & $\geq 30$ & 77 & 67 & 10 & 10 & \\
\hline \multirow[t]{2}{*}{ Overall } & $\mathrm{N}$ & 20 & 17.5 & 54 & 54 & \multirow[t]{2}{*}{0.000} \\
\hline & $A B$ & 95 & 82.6 & 46 & 46 & \\
\hline
\end{tabular}

$\mathbf{N}=$ Normal Lipid profile. $\mathbf{A B}=\mathbf{A b n o r m a l}$ Lipid profile. Prevalence- High TC $=50.44 \%$, High TG $=67 \%$, High LDL-C $=42 \%$, High VLDL-C $=67 \%$ and Low HDL-C $=73.9 \%$, statistically significant difference in prevalence being observed in all parameters except LDL-C. Overall, prevalence of Dyslipidemia $=82.6 \%$

Mean value of TC, TG, LDL-C \& VLDL-C was increased in Study group. The increase was Highly Significant in case of TG \& VLDL-C, while NonSignificant in case of TC \& LDL-C. HDL-C was Significantly decreased in Study group. Mean values of TC, TG, LDL-C and VLDL-C were in increasing trend with progression of CKD stages ( 3 to 5 ), while $\mathrm{HDL}-\mathrm{C}$ value was in decreasing trend.

Table-4: Prevalence of CKD cases and mean value of various Lipid Profile parameters in various CKD stages.

\begin{tabular}{|c|c|c|c|c|c|c|c|}
\hline CKD Stages & $\begin{array}{l}\text { No. of } \\
\text { cases }\end{array}$ & & TC & TG & HDL-C & LDL-C & VLDL-C \\
\hline 1 & 0 & & - & - & - & - & - \\
\hline 2 & 0 & & - & - & - & - & - \\
\hline \multirow[t]{2}{*}{$3(3 a+3 b)$} & \multirow[t]{2}{*}{5} & Mean & 196.8 & 147.0 & 40.60 & $\begin{array}{l}114.4 \\
0\end{array}$ & 27.20 \\
\hline & & SD & 24.22 & 57.63 & 5.86 & 19.53 & 11.34 \\
\hline \multirow[t]{2}{*}{4} & \multirow[t]{2}{*}{29} & Mean & $\begin{array}{l}199.2 \\
8\end{array}$ & $\begin{array}{l}151.2 \\
8\end{array}$ & 38.17 & $\begin{array}{l}118.7 \\
2\end{array}$ & 30.48 \\
\hline & & SD & 43.59 & 69.86 & 7.40 & 39.14 & 15.90 \\
\hline \multirow[t]{2}{*}{5} & \multirow[t]{2}{*}{81} & Mean & 206.1 & $\begin{array}{l}194.4 \\
4\end{array}$ & 34.73 & $\begin{array}{l}125.4 \\
1\end{array}$ & 37.44 \\
\hline & & SD & 44.33 & 58.78 & 4.99 & 38.39 & 11.31 \\
\hline $\begin{array}{l}\text { Total (Study } \\
\text { group) }\end{array}$ & 115 & Mean & 203.9 & $\begin{array}{l}181.5 \\
0\end{array}$ & 35.85 & & 35.24 \\
\hline
\end{tabular}




\begin{tabular}{|l|l|l|l|l|l|l|l|}
\hline \multicolumn{2}{|c|}{} & SD & 46.46 & 64.37 & 5.95 & 37.89 & 12.98 \\
\cline { 3 - 8 } & & p-value & 0.096 & 0.000 & 0.044 & 0.133 & 0.000 \\
\hline \multirow{3}{*}{ Control Group } & \multirow{2}{*}{100} & Mean & 195.36 & 117.11 & 51.19 & 116.37 & 19.78 \\
\cline { 2 - 7 } & & SD & 27.81 & 30.84 & 10.00 & 28.81 & 4.88 \\
\hline
\end{tabular}

Note: $p$-value $=$ compared to Control group

Table-5: Prevalence of CKD cases and mean value of various Lipid Profile parameters in two Sub-groups (I and II) of Study group. Sub-group $I=$ CKD Stages 1 to 4 (Non- ESRD). Sub-group II=CKD Stage 5 (ESRD).

\begin{tabular}{|l|l|l|c|c|c|c|l|}
\hline Sub-group & No. of cases & & TC & TG & HDL-C & LDL-C & VLDL-C \\
\hline \multirow{4}{*}{ I } & \multirow{2}{*}{34} & Mean & 198.91 & 150.65 & 38.53 & 118.09 & 30.00 \\
\cline { 3 - 8 } & & SD & 41.04 & 67.42 & 7.17 & 36.72 & 15.22 \\
\cline { 3 - 8 } & & p-value & 0.641 & 0.008 & 0.000 & 0.780 & 0.000 \\
\hline \multirow{4}{*}{ II } & \multirow{3}{*}{ Mean } & 206.10 & 194.44 & 34.73 & 125.41 & 37.44 \\
\cline { 3 - 8 } & & SD & 44.33 & 58.78 & 4.99 & 38.39 & 11.31 \\
\cline { 3 - 8 } & & p-value & 0.060 & 0.000 & 0.000 & 0.081 & 0.000 \\
\cline { 3 - 8 } & & $\mathrm{p}^{\prime}$-value & 0.419 & 0.001 & 0.007 & 0.347 & 0.013 \\
\hline Control group & 100 & Mean & 195.36 & 117.11 & 51.19 & 116.37 & 19.78 \\
\cline { 3 - 8 } & & SD & 27.81 & 30.84 & 10.00 & 28.81 & 4.88 \\
\hline
\end{tabular}

In both Subgroup I and Subgroup II as compared to Control group, mean TG \& VLDL-C were increased (statistically highly significant), HDL-C was decreased (statistically highly significant).TC \& LDL$\mathrm{C}$ were increased but not significantly.

In Subgroup-II (ESRD) as compared to Subgroup-I (Non-ESRD), mean TG and VLDL-C were increased (statistically highly significant), while value of HDL-C was decreased (statistically highly significant). TC and LDL-C were increased but not significantly.

Note: p-value=compared to Control group. p'value=compared to Sub-group $I$.

Table-6: Correlation of Lipid profile parameters with GFR. $(n=115)$

\begin{tabular}{|c|l|c|c|c|c|c|l|}
\hline & & GFR & TC & TG & HDL-C & LDL-C & VLDL-C \\
\cline { 2 - 8 } & Gearson Correlation & 1 & -0.100 & -0.307 & 0.324 & -0.109 & -0.276 \\
\cline { 2 - 8 } & p-value & & 0.286 & 0.001 & 0.000 & 0.246 & 0.003 \\
\hline
\end{tabular}

TC, TG, LDL-C and VLDL-C showed negative correlation with GFR while HDL-C showed positive correlation. TG, HDL-C and VLDL-C showed statistically highly significant correlation while TC and LDL-C showed non-significantcorrelation. The strongest correlation was observed with HDL-C $(0.324)$, followed by TG $(-0.307)$.

Note: Mean GFR= $11.75 \pm 7.93 \mathrm{~mL} / \mathrm{min} / 1.73$ m2

\section{Discussion}

Age and Gender- In Study group, maximum $23.47 \%$ cases were in fifth decade; mean age was $48.99 \pm 16.74$ \& Male: Female ratio was 1.21: 1.In Control group, maximum $28 \%$ cases were in third decade; mean age was $44.12 \pm 17.61$ \& Male: Female ratio was 1.17: 1 .

Similar observations were obtained by Aharwar et al in 2015 with mean age of patients and controls was $47 \pm 16$ yrs and $47.68 .46 \pm 15.95$ yrs respectively \& Male: Female ratio 1.27: 1[12]. Avasthi $G$ et al in 2001 obtained similar age distribution [13]. Jungers $P$ et al in 1996 had similar Gender distribution with a marked preponderance of males [14].

\section{Lipid profile parameters}

Prevalence: The prevalence of individual dyslipidemias was High $\mathrm{TC}=50.44 \%$, High $\mathrm{TG}=$ $67 \%$, High LDL-C value $=42 \%$, High VLDL-C $=67 \%$ and Low HDL-C $=73.9 \%$, statistically significant difference in prevalence being observed in all parameters except LDL-C.

Garg et al in 2015 in their study of 100 CKD patients observed that $97 \%$ had elevated TG values, $61 \%$ had elevated TC values, $34 \%$ had elevated LDL-C values and $87 \%$ had low HDL-Cvalues [15].

Overall, prevalence of Dyslipidemia was $82.6 \%$ in CKD patients, which was significantly higher as compared to Control group (46\%). The NHANES study in United States observed prevalence of dyslipidemia varying from $48 \%$ in CKD stage $1-2$ to $80 \%$ in CKD stage 3-4[3]. This is in concordance with the present study as the Study group comprised of patients in CKD stages 3 to 5 only.

Summarizing the observations (irrespective of CKD stage): In present study, mean value of TC, TG, LDL-C \& VLDL-C was increased in Study group. The increase was statistically Highly Significant in case of TG \& VLDL-C, while Non- Significant in case of TC \& LDL-C. HDL-C was statistically significantly decreased in Study group.

Shah B et al in 1992 studied Lipid profile in CKD patients and observed no change in TC, HDL-C and LDL-C but there was significant increase in TG level [16]. Koch et al in 1994 observed significant decrease in HDL-C but no change in values of TC, LDL-C and TG[17]. Crook et al in 2003 obtained significant increase in LDL and VLDL-Cwith significant decrease in HDL-C [18]. 
Raju et al in 2013 in their study of 95 CKD patients obtained significant increase in TG and VLDL-C levels and statistically significant decrease in HDL-C levels, but no change in TC and LDL levels[8]. Mannagi et al in 2014 in their study of 30 CKD patients obtained significant increase in TG and LDLC [19].

Aharwar et al in 2015 in their study of 100 CKD patients obtained significant increase in TG and VLDL-C and significant decrease in HDL-C levels. The values of TC and LDL-C were increased but not significantly [12]. The observations of Lipid profile parameters in present study are, thus, similar to that obtained by Raju [8] et al and Aharwar [12] et al.

\section{Summarizing the observations in various} stages of CKD: In present study, values of TC, TG, LDL-C and VLDL-C were in increasing trend with progression of CKD stages (3 to 5), while HDL-C value was in decreasing trend.

In both Subgroup I and Subgroup II as compared to Control group, mean TG \& VLDL-C were increased (statistically highly significant), HDL-C was decreased (statistically highly significant).TC \& LDL$\mathrm{C}$ were increased but not significantly.

In Subgroup-II (ESRD) as compared to Subgroup-I (Non-ESRD), mean TG and VLDL-C were increased (statistically highly significant), while value of HDL-C was decreased (statistically highly significant). TC and LDL-C were increased but not significantly.

A study by Bhagwat et al, 1997 observed dyslipidemia to be independent of serum creatinine levels [20]. A study by Rao et al, 2010 observed significantly high VLDL-Clevels in all stages of CKD 1-5; highTC, LDL-C,TG \& HDL-Clevels in earlier CKD stages while showing decreasing levels in CKD stage 5[21]. Noor et al (2014) observed increase in the values of TC, TG and VLDL-C while decrease in the values of HDL-C with progression of CKD stages.

Values of LDL-C showed decreasing trends in CKD stage 4 and 5 [22]. Aharwar et al (2015) observed value of TG, LDL-C and VLDL-C to be progressively increasing with successive CKD stages while HDL-C value to be progressively decreasing with successive CKD stages. TC value was showing increasing trend from CKD Stage 2 to 4 but in Stage 5, value was lower than Stage 4 [12]. A recent study by Garg et al, 2015 showed statistically significant increase in the values of TG, TC, VLDL-C and TC/HDL-C with the progression of the stages of CKD [15].
Thus, the observations of Lipid profile parameters in various stages of CKD in present study were, more or less, similar to those obtained by Aharwar [12] et al, Garg et al[15] and Noor [22] et al.

Correlation with GFR:In study group, TC, TG, LDL$C$ and VLDL-C showed negative correlation with GFR while HDL-C showed positive correlationi.e. with decreasing GFR, HDL-C level were also decreasing.

TG, HDL-C and VLDL-C showed statistically highly significant correlation while TC and LDL-C showed non-significant correlation.

The strongest correlation was observed with HDL-C (0.324), followed by TG $(-0.307)$. Aharwar et al (2015) also observed negative correlation of TC, TG, LDL-C and VLDL-C with GFR while positive correlation of HDL-C with GFR. But they observed the strongest correlation with TG $(-0.543)[12]$.

\section{Conclusion}

Patients with CKD are predisposed to accelerated atherosclerosis leading to increased cardiovascular complications. Several factors contribute to atherogenesis, most notable among which is dyslipidemia. TC, TG, LDL-C, VLDL-C increase and HDL-C decrease in $C K D$, however significant derangement is seen in levels of TG, VLDL-C and HDL-C.

Dyslipidemia in CKD tends to worsen as the disease (stage of CKD) progresses with statistically significant increase in the values of TG and VLDL-C and statistically significant decrease in the values of HDL-C from Non-ESRD stages to ESRD. TC and LDL$C$ also increase with the progression of disease but not significantly.

\section{What this study adds to existing knowledge?}

This study reconfirms the presence of atherogenic lipid profile in patients of CKD leading to increased cardiovascular risk. The dyslipidemia tends to worsen with progression of CKD from Non-ESRD to ESRD, the most notable lipid abnormality being Low HDL-C.

\section{Limitations}

Most of the patients in our study presented in late stages of CKD (3-5). The sample size of study was small. 


\section{Reference}

01. Dan L Longo, Dennis L Kasper, J Larry Jameson, Anthony S Fauci, Stephen L Hauser, Joseph Loscalzo. Harrisons Principles of Internal Medicine. 18th Ed, New Delhi, McGraw- Hill. $2012 ; 2 ; 2308$.

[Crossref]

02. Liu M, Li XC, Lu L, et al. Cardiovascular disease and its relationship with chronic kidney disease.

Eur Rev Med Pharmacol Sci. 2014 Oct; 18(19)2918-26.

[Crossref]

03. US Renal Data System (USRDS). "Chronic kidney disease in the adult NHANES population". USRDS Annual Report Data. 2009.

Available at: [Article] [Crossref]

04. Johnson DW, Craven AM, Isbel NM. Modification of cardiovascular risk in hemodialysis patientsan evidence-based review. Hemodial Int. 2007 Jan;11(1)1-14.

DOI: $10.1111 / j .1542-4758.2007 .00146 . x$ [Crossref]

05. Harnett JD, Foley RN, Kent GM, et al. Congestive heart failure in dialysis patientsprevalence, incidence, prognosis and risk factors. Kidney Int. 1995 Mar;47(3)884-90. [Crossref]

06. Lewington S, Whitlock G, Clarke R, Sherlinker P, Emberson J, Halsey J, et al. Blood cholesterol and vascular mortality by age, sex and blood pressure a meta-analysis of individual data from 61 prospective studies with 55,000 vascular deaths. Lancet. 2007;370;1829-39.

[Crossref]

07. Vishwam Pandya, Akhilesh Rao, Kunal Chaudhary. Lipid abnormalities in kidney disease and management Strategies. World J Nephrol. 2015; Feb-6;4(1)83-91.

[Crossref]

08. DSSK Raju, DL Lalitha, P Kiranmayi. A Study of Lipid Profile and Lipid Peroxidation in Chronic Kidney Disease with Special Reference to Hemodialysis. J Clinic Res Bioeth. 2013;4;143.

DOI: 10. 4172/2155-9627.1000143 [Crossref]
09. Kimak E, Solski J, Janicka L, Ksazeik A, Janicki K. Concentration of LP (a) and other apolipoproteins in predialysis, haemodialysis, chronic ambulatory peritoneal dialysis and posttransplant patients. Clin Chem Lab Med. 2000;38(5)421-5.

DOI: 10.1515/CCLM.2000.061 [Crossref]

10. Cheung AK, Parker $\mathrm{CJ}$, Ren $\mathrm{K}$, Iverius $\mathrm{PH}$. Increased lipase inhibition inuremiaIdentification of pre-beta $\mathrm{HDL}$ as a major inhibitor in normal and uremic plasma. Kidney Int. $1996 ; 49(5) 1360-7$.

[Crossref]

11. Oluseyi A Adejumo, Enajite I Okaka, Louis I Ojogwu. Lipid profile in pre-dialysis chronic kidney disease patients in southern Nigeria. 2016;Mar;50(1).

[Crossref]

12. Aharwar S, Lahariya D. A study of lipid profile in chronic kidney disease in non-diabetic patients. Journal of Evolution of Research in General Medicine. 2015;1(1)16-20.

[Crossref]

13. Avasthi G, Malhotra M, Narang A, Sengupta S. Study of thyroid function test in patients of chronic renal failure. Indian J Nephrol. $2001 ; 11 ; 165-9$.

[Crossref]

14. Jungers $P$, Chauveau $P$, Descamps-Latscha $B$, Labrunie M, Giraud E, Man NK, Grünfeld JP, Jacobs $C$. Age and gender-related incidence of chronic renal failure in a French urban area- a prospective epidemiologic study. Nephrol Dial Transplant. 1996 Aug;11(8)1542-6.

[Crossref]

15. Gourav Garg, Sumit Pal Singh Chawla and Sarabjot Kaur. A clinical study of dyslipidemia in patients of chronic kidney disease. International Journal Of Bioassays. Jan 23;2015;4 (03)37323737.

[Crossref]

16. Shah BV, Nair S, Sirsat RA. Outcome of end stage renal disease. J of Nephrol New Series. $1992 ; 2 ; 151-153$.

[Crossref]

17. Koch A, Shan B, Nair S, Sirsat R, Ashavoid T, Nair K. Dyslipidemia in patients with chronic renal failure and in renal transplant. Journal of Postgraduate Medicine. 1994;40(2)57-60. [Crossref] 
18. Crook ED, Thallapureddy A, Migdal S, et al. Lipid abnormalities and renal disease- is dyslipidemia a predictor of progression of renal disease?. Am J Med Sci. 2003 Jun;325(6)340-8.

[Crossref]

19. Mannangi N, Jayasree S. Lipoprotein(a) \& Lipid profile in Chronic kidney disease- Case control study. Central BIOCHEMISTRY. $2014 ; 5(2) 004568$.

Doi: 10.9754/journal.wmc.2014.004568 [Crossref]

20. Rajesh Bhagwat, S P Joshi, Pradeep Salgia, and Achal Sepaha. Lipid abnormalities in chronic renal failure. Indian J Clin Biochem. 1997 Dec;12(1)81-85.

[Crossref]
21. A M Rao, A R Bitla, E P Reddy, V Sivakumar, P V L N Srinivasa Rao. Lipid Abnormalities, Lipoprotein (A) And Apoprotein Pattern in NonDialyzed Patients with Chronic Kidney Disease. Indian Journal of Clinical Biochemistry. $2010 ; 25(1) 47-50$.

doi: 10.1007/s12291-010-0010-5 [Crossref]

22. Sabeela Noor, Nudrat Anwar Zuberi, Fasiha Fatima, TahseenIqbal, Khalilullah. Status of Lipid Profile in Different Stages of Chronic Kidney Disease. Annals of Abbasi Shaheed Hospital \& Karachi Medical \& Dental College. 2014;19(2)62-66.

[Crossref] 